\title{
Effects of Maozhaocao polysaccharide on the thymus and spleen of Immunosuppressive Model Mice
}

\author{
Miao Mingsan ${ }^{1 \mathrm{a}}$ Tan Wang ${ }^{1}$ Yan $\mathrm{Li}^{1}$ Zekai Hu$^{1}$ Jingyi Qiao ${ }^{1}$ Huili Liu ${ }^{1}$ \\ ${ }^{1}$ Henan university of traditional Chinese medicine, zhengzhou,henan,China45000 \\ a email: miaomingsan126.com
}

Keywords: Maozhaocao, Immunosuppressive, cyclophosphamide, thymus , spleen

\begin{abstract}
The objective of this experiment is to investigate the effect of Maozhaocao polysaccharide on the thymus and spleen of Immunosuppressive Model Mice. Study the Immunosuppressive model of mice by using cyclophosphamide, for the large, medium and small dose of Maozhaocao polysaccharide, Mushrooms polysaccharide, and contral group. The mice were treated $7 \mathrm{~d}$. Take thymus and spleen for pathological section. Maozhuacao can significantly increased the number of thymus cortex and cortex cells in the model animals, and increased the number of spleen nodules and lymphocytes in the model. Conclusion: Maozhaocao could significantly resist the atrophy of the thymus and spleen of the model.
\end{abstract}

\section{Introduction}

Maozhaocao is the roots of Buttercup Ranunculus. Maozhaocao is sweet, acrid, warm, liver, lung, phlegm, detoxification detumescence[1]. Written records is first seen in the Chinese herbal medicine manual. Maozhaocao is a kind of herb found in Xinyang, Henan Province in 1950s. Maozhaocao in Folk is mainly used for the treatment of cervical lymph node tuberculosis, mumps[2]. Chinese Academy of Medical Sciences Institute of Medicine: cat's paws 16\%, Oil 1.2\%, trace alkaloids. This experiment studied the effects of Maozhaocao on Immunosuppressive Model Mice.

\section{Material}

2.1 experimental drugs: Maozhaocao: kaikaiyuansheng medicine provided by Limited Share Ltd, polysaccharide of Radix Ranunculi ternati provided by the Institute of chemistry, grinding, degreasing, water extraction, concentration, alcohol precipitation, deproteinization, dialysis and vacuum drying; lentinan tablets, Zhejiang Apeloa natural medicine limited, lot 060701.

2.2 animal: Kunming mice, male and female, weighing $18 \sim 22 \mathrm{G}$, animal Certificate No. 703003, provided by the Hebei Province medical experimental animal center, license No. SCXK (Hebei) 2003-1-003.

2.3 reagents: cyclophosphamide, Shanxi Pude Pharmaceutical Co. Ltd., No. 20070102.

2.4 instruments: UV 2000 spectrophotometer, unique instrument (Shanghai) Co. 1td..

\section{3 methods and results}

60 mice, male and female, were randomly divided into 6 groups, 5 groups of these mice induced by cyclophosphamide immunosuppression model [4], in 3 days before administration of intraperitoneal injection of cyclophosphamide (dose $80 \mathrm{mg} / \mathrm{kg}, 0.2 \mathrm{ml} / 10 \mathrm{~g}$ each time). On the first day, the 5 groups were fed with large, medium and small doses of the cat's paw polysaccharide suspension $(0.1 \mathrm{ml} / 10 \mathrm{~g}$, $450300150 \mathrm{mg} / \mathrm{kg}, 0.1 \mathrm{ml} / 10 \mathrm{~g})$, and the same volume of saline solution $(150 \mathrm{mg} / \mathrm{kg})$. Another 1 groups of blank control group were given the same volume of saline $(0.1 \mathrm{ml} / 10 \mathrm{~g})$. 1 times a day, continuous administration of $7 \mathrm{~d}$. At the end of the administration of $2 \mathrm{~h}$, the mice were sacrificed by 
cervical dislocation, thymus and spleen, 10\% formalin fixed, sectioning for inspection [5], to observe the effect of Radix Ranunculi ternati polysaccharide on the immune suppression model of thymus and spleen tissue morphology under microscope. The results are shown in Table 1, table 2 .

Table 1 Effects of CY on the morphology of thymus in mice immunized with Maozhuacao

\begin{tabular}{|c|c|c|c|c|}
\hline group & $\mathrm{n}$ & $\begin{array}{l}\text { dose } \\
(\mathrm{mg} / \mathrm{kg} \\
)\end{array}$ & $\begin{array}{c}\text { Thymic cortex } \\
\text { thickness } \\
(\mu \mathrm{m})\end{array}$ & $\begin{array}{c}\text { Lymphocyte } \\
\text { number } \\
(\mathrm{n})\end{array}$ \\
\hline Control group & 10 & & $26.27 \pm 5.46^{* *}$ & $42.65 \pm 8.22 * *$ \\
\hline Model group & 10 & & $8.27 \pm 1.47$ & $10.11 \pm 1.03$ \\
\hline Mushrooms polysaccharide group & 10 & 150 & $12.14 \pm 2.30 * *$ & $14.44 \pm 2.78 * *$ \\
\hline $\begin{array}{l}\text { Large dose of Maozhaocao } \\
\text { polysaccharide group }\end{array}$ & 10 & 450 & $23.65 \pm 4.12 * *$ & $38.26 \pm 6.37 * *$ \\
\hline $\begin{array}{l}\text { medium Maozhaocao } \\
\text { polysaccharide group }\end{array}$ & 10 & 300 & $18.74 \pm 6.24 * *$ & $32.18 \pm 4.26^{* *}$ \\
\hline $\begin{array}{l}\text { Small Maozhaocao polysaccharide } \\
\text { group }\end{array}$ & 10 & 150 & $12.36 \pm 1.32 * *$ & $14.22 \pm 2.17^{* *}$ \\
\hline
\end{tabular}

compared with the model group, the model group was less than $\mathrm{P}<0.05$, and the model group was less than $\mathrm{P}<0.01$

From table 1, compared with the control group, the model group showed that the cortical thickness of the model group was significantly decreased $(\mathrm{P}<0.01)$, and the number of lymphocytes was significantly decreased $(\mathrm{P}<0.01)$. Compared with the model group, the large, medium and small dose of Maozhucao polysaccharide group were significantly increased in the thymus cortex $(\mathrm{P}<$ $0.01)$, and the number of lymphocytes was significantly increased $(\mathrm{P}<0.01)$.

Histological observation of spleen: The control group, a clear demarcation between red and white pulp of spleen, spleen summary, and lymphocyte dense. The model group of spleen red and white pulp boundaries clear, However, the spleen nodules were significantly decreased, and the sparse cells were significantly decreased; Mushrooms polysaccharide group was a clear demarcation between red and white pulp, The spleen has a slight recovery, the peripheral lymphocytes are sparse and the central intensive; A large dose of Maozhaocao polysaccharide group clear demarcation between red and white pulp of spleen. Spleen summary got some recovery, and lymphocyte density increased. In the medium Maozhaocao polysaccharide group clear demarcation between red and white pulp of spleen. The spleen was enlarged and the spleen was enlarged. Lymphocyte density increased slightly. Small Maozhaocao polysaccharide group were relatively clear boundary between red and white pulp. Splenic nodules increased, and lymphocytes were sparse. 
Annex 1: effect of Miaozhuacao polysaccharide on the spleen of Immunosuppressive Model Mice

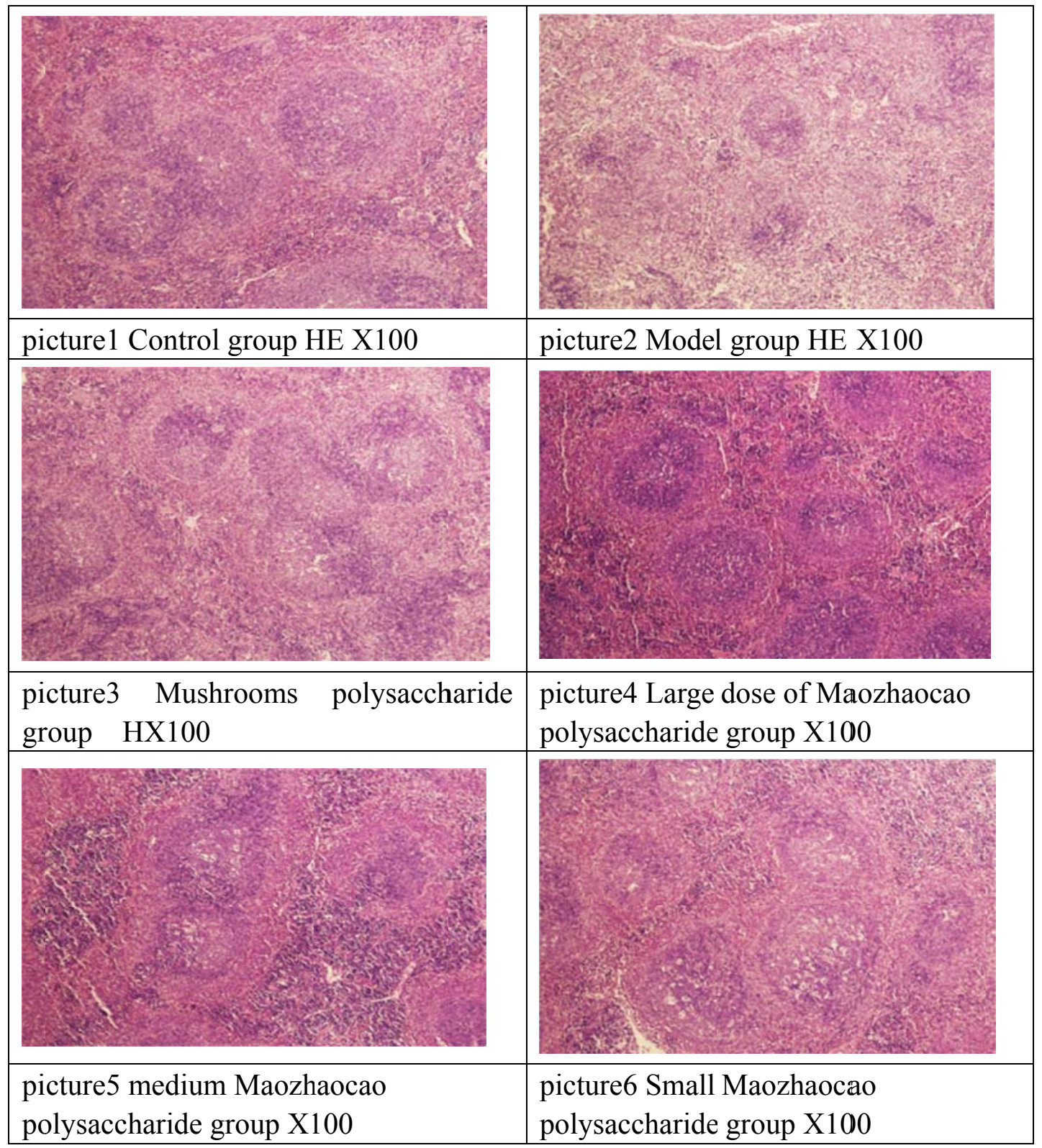

Table 2 Effects of CY on the morphology of spleen in mice immunized with Maozhucao

\begin{tabular}{|c|c|c|c|c|}
\hline group & $\mathrm{n}$ & $\begin{array}{l}\text { dose } \\
(\mathrm{mg} / \mathrm{kg} \\
\quad)\end{array}$ & $\begin{array}{l}\text { Spleen section } \\
\text { size } \\
(\mu \mathrm{m})\end{array}$ & $\begin{array}{c}\text { Lymphocyte } \\
\text { number } \\
\text { (n) }\end{array}$ \\
\hline Control group & 10 & & $20.17 \pm 4.78 * *$ & $30.27 \pm 4.23 * *$ \\
\hline Model group & 10 & & $7.21 \pm 1.12$ & $10.36 \pm 2.38$ \\
\hline $\begin{array}{c}\text { Mushrooms } \\
\text { polysaccharide group }\end{array}$ & 10 & 150 & $11.08 \pm 2.17 * *$ & $12.13 \pm 2.36$ \\
\hline $\begin{array}{l}\text { Large dose of Maozhaocao } \\
\text { polysaccharide group }\end{array}$ & 10 & 450 & $16.27 \pm 2.35 * *$ & $18.37 \pm 2.19 * *$ \\
\hline $\begin{array}{l}\text { medium Maozhaocao } \\
\text { polysaccharide group }\end{array}$ & 10 & 300 & $14.18 \pm 2.26 * *$ & $16.28 \pm 3.24 * *$ \\
\hline $\begin{array}{l}\text { Small Maozhaocao } \\
\text { polysaccharide group }\end{array}$ & 10 & 150 & $12.34 \pm 1.32 * *$ & $15.76 \pm 3.72 * *$ \\
\hline
\end{tabular}


compared with the model group, the model group was less than $\mathrm{P}<0.05$, and the model group was less than $\mathrm{P}<0.01$

From table 2, compared with the blank control group, the spleen of the model group was significantly smaller $(\mathrm{P}<0.01)$, and the number of lymphocytes was significantly reduced $(\mathrm{P}<$ 0.01). Compared with the model group, large, medium and small dose of Maozhaocao polysaccharide and Mushrooms polysaccharide group could significantly increase the volume of splenic nodule $(\mathrm{P}<0.01)$, significantly increased lymphocyte number $(\mathrm{P}<0.01)$, in the large and middle dose of Maozhaocao polysaccharide group was better.

Annex 2: the effect of Maozhucao polysaccharide on the thymus of Immunosuppressive Model

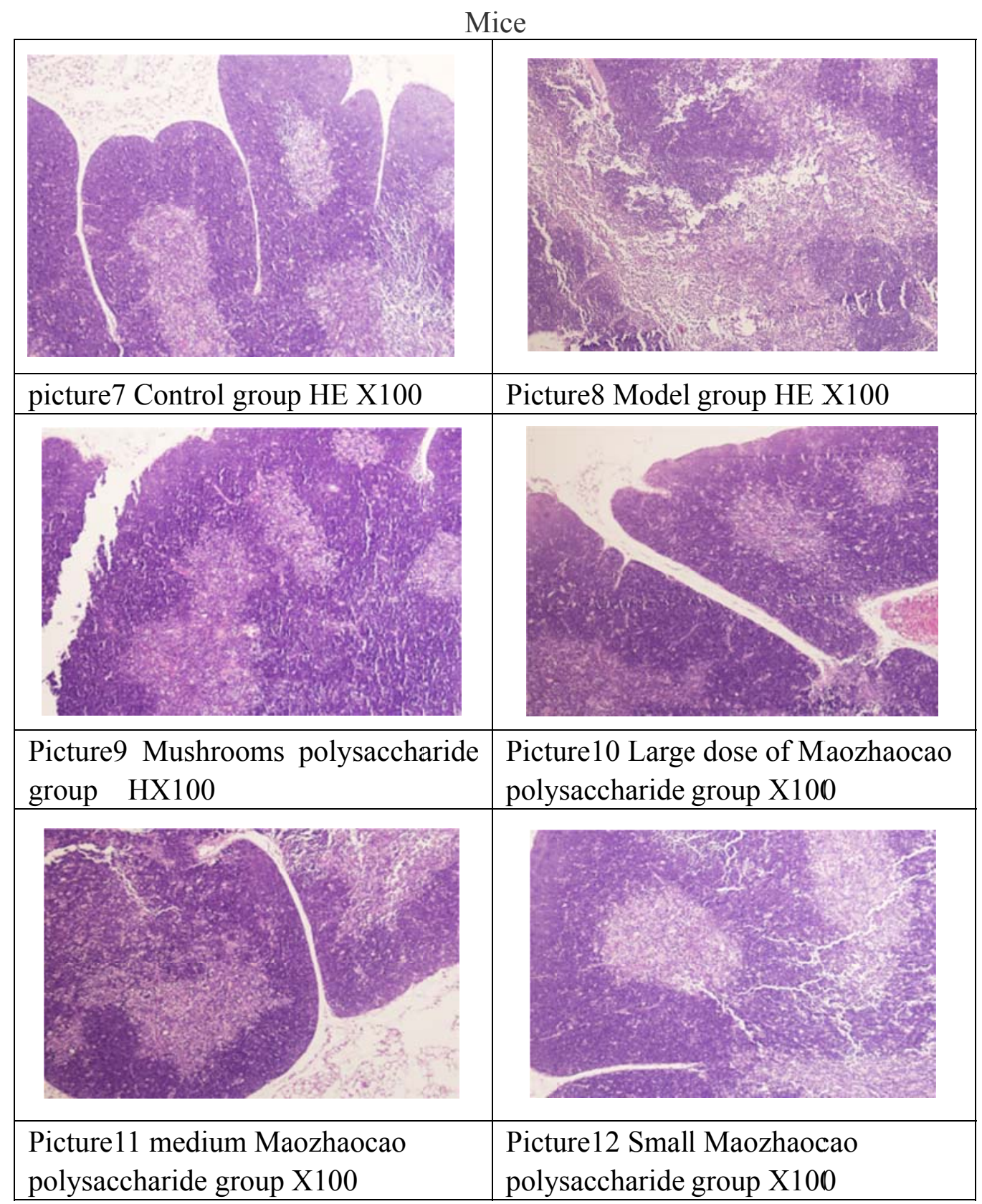

\section{4 discussion}

Immune system has the function of immune defense, immune surveillance and immune function, the body's immune system is to resist the external pathogenic bacteria and in vivo abnormal cells [6] by identifying, swallowing, presenting and secreting cytokines. Cyclophosphamide (CY) is an alkylating agent nitrogen mustard derivatives, synthesis of [7] nucleic acid interference cell, and can kill the mitotic cycle and enter the cell, can inhibit the immune, therefore in immunological research, 
drug preparation of [8] used in CY as cellular immunity and humoral immunity disease the inhibition model.

Previous studies have focused on the activities of the extracts of the activity of Maozhaocao polysaccharide and spleen are important immune organs, the thymus is the development of T cells, and the spleen is the body's largest immune organ. It is the center of cellular immunity and humoral immunity. The quality of thymus and spleen in a certain extent can reflect the immune function of [9].

\section{Conclusion}

In this experiment, we studied the effects of different doses of Polysaccharide on Immunosuppressive Model model of mouse thymus and spleen. The results showed that the significant increase in the number of the thymus cortex, spleen, and spleen were significantly increased, and the effect of the large and medium dose of Maozhaocao polysaccharide was superior. It is suggested that the polysaccharide of the Maozhuacao has a good effect on the atrophy of immune organs, which can improve the immune function of the body. This study also suggested that the main components of the immune system were the Maozhucao polysaccharide.

\section{References}

[1] National Pharmacopoeia Committee. Chinese Pharmacopoeia, I [S]. Beijing: Chemical Industry Press, 2005:223.

[2] Wu Zongyao, Miao three, Jiang Shiqing. Study on the immune function effect of [J]. on tumor bearing mice, 2014,29 (188): 58-60.

[3] Miao Yaodong, Li Xiaojiang, Jia Yingjie. Progress on chemical constituents and pharmacological effects of cat's paw [J]. Chinese herbal medicine, 2014,11 (45): 1651-1654.

[4] Zhang Lifeng, Pu Jianzhong, Bao Yingcun. Compared with a compound with Radix Hedysari and influence inhibition of lymphocyte and Th1/Th2 type cytokines on the immune mice with Huangqi Journal [J]. Immunology, 2012,28 (3): 212-216.

[5] Liu Huili, Hu Zekai, Qiao Jingyi, Miao three. The effect of [J]. on the immune function of mice immunized with cyclophosphamide induced by cyclophosphamide , 2010,27 (2): 89-91.

[6] Liu Junli, Song Shujun, Xu Bingxin. Effects of vitamin [J]. on immune function in mice with glucocorticoid immune suppression D Chinese Journal of clinical medicine (electronic version).2013,7 (23): 10s02-10s05.

[7] Li Ze, Shen Jianli, Pan Deng. Experimental study on the effects of the polysaccharide on the immune function of mice [J].Pharmaceutical biotechnology.2013,20 (3): 241-244.

[8] Zhang Lifeng, Cheng Weidong, GUI Manman.A comparative study of Astragalus Radix Hedysari to replace the wind of Yuping oral liquid in the inhibition of cellular immunity in mice immunized with [J].Chinese herbal medicine.2012,35 (2): 269-273.

[9] Yan love, Li Bo, Li Runcheng. Studies on the regulation of immune function in mice with immune suppression by polysaccharide and Astragalus Polysaccharides[J]. Chinese Journal of immunology.2012,28:999-1005. 